Published in Journal of Neurotroma 22 (6): 703-717, 2005

\title{
A unilateral section of the corticospinal tract at cervical level in primate does not lead to measurable cell loss in motor cortex.
}

T. Wannier ${ }^{1,2,{ }^{*}}$, E. Schmidlin ${ }^{1, *}$, J. Bloch $^{3}$ and E.M. Rouiller ${ }^{1}$

* The first two authors contributed equally to the study.

(1) Unit of Physiology and Program in Neurosciences, Department of Medicine, Faculty of Sciences, University of Fribourg, Chemin du Musée 5, $\mathrm{CH}-1700$ Fribourg, Switzerland.

E-mails: thierry.wannier@unifr.ch eric.schmidlin@unifr.ch $\quad \underline{\text { eric.rouiller@unifr.ch }}$

(2) Brain Research Institute, Dept. Neuromorphology, University and ETH Zurich, Winterthurerstr. 190, CH-8057 Zürich, Switzerland.

(3) Dept. of Neurosurgery, Neurosurgery Clinic, University Hospital of Lausanne, Rue du Bugnon, $\mathrm{CH}-1011$ Lausanne, Switzerland.

E-mail: Jocelyne.Bloch@chuv.hospvd.ch

Running title: Survival of CS neurons after spinal cord lesion

Text pages: 31

Tables: 0

Figures: 4

Main body of text: 7611 words, 40359 characters

Abstract: 211 words

Grant Sponsors: Swiss National Science Foundation, grants No 31-43422.95, 4038-43918, 3161857.00 (EMR); Novartis Foundation; The National Centre of Competence in Research (NCCR) on "Neural plasticity and repair".

* Address for correspondence: Prof. Eric M. Rouiller, Unit of Physiology, Chemin du Musée 5, CH-1700 Fribourg, Switzerland. Phone: 00412630086 09. Fax: 00412630096 75. E-mail: Eric.Rouiller@unifr.ch 


\section{Abstract}

The effects of a unilateral interruption of the dorsolateral funiculus at cervical level on the survival of motor cortex neurons was investigated in macaque monkeys. The lesion was set on the left side at the transition region between the $7^{\text {th }}$ and $8^{\text {th }}$ cervical segments, above the motoneurons controlling hand muscles. As a result, the homolateral hand became paretic although an incomplete recovery of manual dexterity took place during 2 months post-lesion. A quantitative anatomical assessment of pyramidal neurons in layer $\mathrm{V}$ was performed in the hindlimb area of the primary motor cortex and in the supplementary motor area (SMA-proper). The pyramidal neurons were visualized using the marker SMI-32 and thus included the subpopulation of corticospinal neurons. These quantitative data demonstrated that the vast majority of the axotomized corticospinal neurons did not degenerate but their soma shrank, as compared to the opposite hemisphere or to intact monkeys. This conclusion is in contrast with some previous studies in monkeys arguing for a substantial degeneration of motor cortex neurons as a result of transection of the corticospinal tract, but in agreement with others concluding to a survival of most CS neurons. However, the survival of most CS axotomized neurons is consistent with the observation of numerous CS axons $1 \mathrm{~mm}$ above the cervical hemi-section.

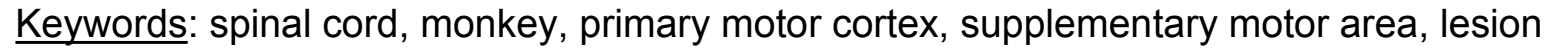




\section{Introduction}

Several studies in monkeys have examined the effects of interrupting the corticospinal (CS) tract at various levels along its pathway towards their targets in the spinal cord. In particular, investigations assessed the consequences of pyramidotomy, a lesion aimed at selectively interrupting the CS axons originating from one - or in the case of bilateral pyramidotomy - from both hemispheres (Beck and Chambers 1970; Bucy 1957, 1966; Chapman and Wiesendanger 1982; Hepp-Reymond and Wiesendanger 1972; Hepp-Reymond et al., 1974; Kucera and Wiesendanger 1985; Lawrence and Kuypers 1968; Lawrence and Hopkins 1976; Schwartzmann 1978; Tower 1940; Woolsey et al., 1972). As reviewed in detail (Hepp-Reymond 1982), recovery after pyramidotomy in monkeys is variable and depends upon the precise location and extent of the lesion, post-lesion survival, and evaluation of types of movements and/or behaviour.

Other studies assessed the deficits associated with interruption of the CS tract at a segmental level in monkeys (Aoki and Mori 1979; Bernhard et al., 1953; Denny-Brown 1966; Galea and Darian-Smith 1997a,b; Holmes and May 1909; Mettler 1944; Sasaki et al., 2004; Schmidlin et al., 2004). A surprisingly good and rapid recovery of dexterous finger movements of the ipsilateral hand took place after hemisection at C3 level in either newborn and juvenile monkeys (Galea and Darian-Smith 1997a,b), or in adult monkeys after hemisection at C4/C5 (Sasaki et al., 2004) or C7/C8 level (Schmidlin et al., 2004). Retrograde tracing experiments showed that, immediately after the $\mathrm{C} 3$ hemisection and later on during the recovery, there was a dramatic reduction of the CS projection to the hemicord caudal to the lesion (Galea and Darian-Smith 1997a). The authors concluded that the recovery of manual dexterity was not due to a substantial reconstruction of the lesioned projection but rather to enhancement of the transmission of information from cortex to spinal cord in a reduced number of CS and/or corticobulbospinal projections together with a contribution of effective use of spinal circuits.

As discussed above, most studies conducted in monkeys subjected to a lesion of the corticospinal tract were aimed at assessing the consequences of the lesion on the motor control. Relatively few studies addressed anatomically the question of the degeneration versus survival of 
axotomized CS neurons. Based on Nissl stained material in primates, some earlier anatomical investigations suggested that pyramidotomy (Pernet and Hepp-Reymond, 1975; Wohlfarth, 1932) or cervical cord lesion (Holmes and May, 1909; Levin and Bradford, 1938;) induced the death of a substantial part of the large CS neurons in the contralateral primary motor cortex (M1). For instance, in 3 monkeys, after unilateral pyramidotomy affecting 60, 90 and 100\% of the CS tract, proportions of pyramidal cells in layer $\mathrm{V}$ of 53,35 and $27 \%$, respectively, were found to survive in the motor cortex (Pernet and Hepp-Reymond, 1975). In other words, in contrast to the opposite hemisphere, a nearly complete unilateral pyramidotomy led to a cell loss of about $70 \%$ in the contralateral motor cortex, affecting the large more than the small pyramidal neurons. Another study (Holmes and May, 1909) investigated the effect of a unilateral lesion at cervical level (C1). In a macaque monkey, 157 days post-lesion, there was a great reduction in the number of giant cells in the opposite hemisphere, to about only one thirteenth of the normal number. In a chimpanzee, four weeks after a hemisection at C3, a considerable reduction of giant cells was found in the contralateral hemisphere (Holmes and May, 1909). In humans, 2 cases subjected to a cervical lesion at C7 showed to a dramatic loss of giant cells in the contralateral hemisphere, as observed 100-200 days post-lesion (Holmes and May, 1909). In spite of some variability, in relation to the site of the lesion (pyramidotomy versus cervical lesion) and duration of survival, these studies of CS tract lesion in primates support the notion of a substantial loss of pyramidal neurons in the opposite cortex, preferentially affecting giant cells. Similarly, bilateral transection of the main CS tract at T9 level in the rat was claimed to lead to a cell loss of about $40 \%$, as observed 4 weeks after injury (Hains et al., 2003).

In contrast to the above studies describing cell loss in the cerebral cortex due to retrograde degeneration following lesion of the CS tract, other authors came to the opposite conclusion. In primates (human and monkeys), it was reported that there was no retrograde degeneration with breakdown and loss of neurons after section of the CS tract (Davison 1937; Lassek 1948; Tower 1940). The latter author claimed that the axotomized giant CS cells, the so-called Betz cells, exhibited changes characterized by shrinkage and loss of Nissl substance. In other words, the normal configuration of the axotomized cells was lost, but they survived (Lassek 1948). After 
pyramidotomy in monkeys for instance, evidence for retrograde degeneration of severed axons was found only in the region immediately above the lesion, namely in the pons, but not above, consistent with a survival of the axotomized neurons in the cerebral cortex (Tower 1940). In a human subject with a lumbar lesion, a retrograde degeneration of CS axons was present rostral to the lesion, but not above C5 level (Bronson et al., 1978). In hamsters subjected to unilateral pyramidotomy (Kalil and Schneider 1975), no significant cell loss was observed in the cerebral cortex. However, there was a shrinkage of most large pyramidal cells in layer $\mathrm{V}$. The retrograde degeneration of the transected axons was limited to a distance of 6-7 $\mathrm{mm}$ rostral to the lesion, as observed after 14 months post-lesion (Kalil and Schneider 1975).

The review of the literature above indicates that the issue of cell loss after lesion of the CS tract at pyramidal or segmental level remains controversial. The aim of the present study was therefore to re-examine the issue of cell loss in the cerebral cortex following a hemisection at cervical level (C7) in two macaque monkeys. In contrast to the previous studies in primates conducted on Nissl-stained material, we took advantage of the use of a marker (SMI-32) that preferentially stains pyramidal neurons, including CS neurons, thus allowing better identification of the cells included in the analysis than in Nissl material. The anatomical investigations took place at a time (116 and 194 days post-lesion) when the incomplete behavioural recovery of manual dexterity of the affected hand reached a plateau. In other words, the observations were conducted when there was behavioural and electrophysiological evidence for a relatively stable situation in term of re-organisation of the cerebral cortex (see also Schmidlin et al., 2004).

We established the number and size of pyramidal neurons in layer $V$ of cortical regions from which the CS tract originates in both hemispheres. The data were then compared between the two hemispheres, and could be interpreted as follows. If axotomized CS neurons do not degenerate, then the data should be comparable in the two hemispheres. On the other hand, if degeneration occurs, the hemisphere contralateral to the cervical hemisection may exhibit a decreased number of CS neurons, as compared to the ipsilateral hemisphere. Finally, the data obtained in the two monkeys subjected to cervical hemisection were compared to data derived from two intact animals. 


\section{Materials and Methods}

\section{Overview of the whole experimental protocol}

The present data have been derived from a long-term protocol described earlier (Schmidlin et al., 2004), which can be summarised as follows: Experiments were conducted on four adult (3-8 years old) Rhesus monkeys (Macaca mulatta), in accordance with the Guide for the Care and Use of Laboratory Animals (ISBN 0-309-05377-3; 1996) and approved by local (Swiss) veterinary authorities. Two adult monkeys (Mk1 and Mk2; 3-4 years old), each weighing around 4 kg, were subjected to a hemisection of the cervical cord. On these 2 animals, an intensive pre-lesion training was initally performed in order to establish a stable behavioural score in manual dexterity tasks involving both hands. An extensive somatotopic map was then established in and around the "hand" area in M1 on both hemispheres, using ICMS mapping techniques, as previously reported (Liu and Rouiller 1999; Rouiller et al., 1994a,b, 1996). A unilateral lesion was performed at the $\mathrm{C} 7 / \mathrm{C} 8$ border on the left side and the behavioural performances were assessed at regular intervals for several months post-lesion, until the animals reached a plateau reflecting a high level of spontaneous functional recovery of manual dexterity. The extensive somatotopic map in M1 was then re-established post-lesion in order to determine whether plastic changes took place during the recovery period. Finally, reversible inactivation techniques were applied in order to identify cortical territories possibly contributing to the incomplete recovery of manual dexterity. The behavioural and electrophysiological results derived from these 2 animals are described in a separate report (Schmidlin et al., 2004). The present article is focussed on anatomical aspects dealing specifically with the issue of death/survival of CS neurons after cervical hemisection. Therefore, only the methods relevant to this specific issue will be described in detail below. In addition, the anatomical data derived from the 2 lesioned monkeys were compared with data derived from two intact monkeys (Ctrl1 and Ctrl2; used in Liu et al., 2002), 5 and 8 years old and weighing 5 and 11 kg, respectively. 


\section{$\underline{\text { Surgical procedures }}$}

Anaesthesia was induced by intramuscular (i.m.) injection of ketamine (Ketalar®; ParkeDavis, $5 \mathrm{mg} / \mathrm{kg}$, i.m.). Atropine was injected i.m. (0.05 mg/kg) to reduce bronchial secretions. Before surgery, the animal was treated with the analgesic Carprofen (Rymadil ${ }^{2}, 4 \mathrm{mg} / \mathrm{kg}$, s.c.). An intravenous catheter was placed in the femoral vein for continuous perfusion with a mixture of propofol $1 \%$ (Fresenius $\AA$ ) and a $4 \%$ glucose solution ( 1 volume of Propofol and 2 volumes of glucose solution), to induce a deeper anaesthesia. The animal was then placed in a stereotaxic framework. During the surgery under aseptic conditions, heart rate, respiration rate, expired $\mathrm{CO}_{2}$, arterial $\mathrm{O}_{2}$ saturation and body temperature were monitored. Usually, the level of anaesthesia remained deep and stable at a rate of venous perfusion of the Propofol/glucose mixture of 0.1 $\mathrm{ml} / \mathrm{min} / \mathrm{kg}$. An extra intravenous bolus of $0.5 \mathrm{mg}$ of ketamine diluted in saline $(0.9 \%)$ was added at potentially more painful steps of the surgical procedure, such as laminectomy.

Placed in a ventral decubitus position, the animal had a pillow under his chest and his head was kept in a flexed position ventrally to expose the posterior cervical region. Under sterile conditions, a vertical midline skin incision was performed from C2 to Th1. The fascia was cut and the spinal processes from C2 to Th1 were exposed. The paravertebral muscles were retracted and the laminae of C6, C7 and Th1 were dissected. A complete C6 laminectomy and an upper C7 hemilaminectomy were then performed. The ligamentum flavum was removed. The dura mater was exposed and incised longitudinally. Under the microscope, the dorsal root entry zones were easily identified. To complete the left unilateral section of the spinal cord at the C7/C8 border, the dorsal root entry zone was the most medial landmark. From this target, a surgical blade (no 11, Paragon $($ ) was inserted $4 \mathrm{~mm}$ in depth perpendicularly to the spinal cord, and the section was prolonged laterally to completely cut the dorsolateral funiculus. The rostro-caudal level where the dorsal rootlets entering respectively the $7^{\text {th }}$ and the $8^{\text {th }}$ cervical spinal segments meet, corresponds to the rostral zone of the spinal portion covered by the $6^{\text {th }}$ cervical lamina. The aimed lesion is located caudal with respect to the main pool of biceps motoneurons but rostral to the pools of triceps, forearm and hand muscle motoneurons (Jenny and Inukai 1983). The muscles and the skin were sutured and the animal recovered from anaesthesia usually 15-30 minutes after 
interruption of the venous perfusion with propofol. The animal was treated post-operatively with an antibiotic (Ampiciline 10\%, $30 \mathrm{mg} / \mathrm{kg}$, s.c.). Additional doses of Carprofen were given daily during one week (pills of Rymadil mixed with food). After the spinal lesion, the animal was kept alone in a separate cage for a couple of days, to allow better conditions for recovery than the usual housing in groups with other monkeys. Because these animals will be used as a control group for on-going investigations aimed at assessing the effect of a regenerative treatment, an osmotic pump (Alzet $囚$, 2ML2) delivering a monoclonal mouse IgG (concentration: $3.7 \mathrm{mg} / \mathrm{ml}$, flow: $5 \mu \mathrm{l} / \mathrm{h}$ ) was inserted in the neck muscles and once changed after 2 weeks. In order to deliver the antibody in close proximity of the lesion, the free tip of a polyethylene tube attached to the pump was fixed under the dura few $\mathrm{mm}$ rostrally to the lesion.

\section{Histology}

Twenty-one (Mk1) and thirty-six (Mk2) days before sacrifice of the animal, an anterograde tracer was injected in each hemisphere, in the M1 hand area in order to stain the CS tracts. The anterograde tracer injected in the right hemisphere was Biotinylated Dextran Amine (BDA, Molecular Probe $\AA$ ) whereas, in the left hemisphere, it was the fluorescent anterograde tracer Fluorescein Dextran (Molecular Probe $\left.{ }^{\circledR}\right)$.

The two lesioned monkeys (Mk1 and Mk2) were sacrificed 116 and 194 days post-lesion, respectively. For sacrifice, sedation was first induced with ketamine, as mentioned above, followed by a deep anaesthesia obtained by intraperitoneal (i.p.) injection of a lethal dose of pentobarbital (90 mg/kg). The animals were perfused transcardially with 0.4 litre of $0.9 \%$ saline, followed by 4 litres of fixative ( $4 \%$ solution of paraformaldehyde in $0.1 \mathrm{M}$ phosphate buffer, $\mathrm{pH}=7.6$ ). Perfusion was continued with 3 solutions of sucrose of increasing concentration (10\% in fixative, 20 and 30 $\%$ in phosphate buffer). The brain and the spinal cord were dissected and stored in a $30 \%$ sucrose solution for cryoprotection for 1-2 days. The brain was blocked, in order to focus analysis on the part of the brain extending rostro-caudally from stereotaxic coordinates $2 \mathrm{~mm}$ to $37 \mathrm{~mm}$ (reference interaural plane; see Paxinos et al., 2000). Frozen sections comprising each the two hemispheres were cut in the coronal plane at a thickness of $50 \mu \mathrm{m}$. The spinal cord was cut in the 
paralongitudinal plane at the site of the lesion and transversally at the level of the first cervical segments as well as of thoracic segments caudal to the lesion. The sections were distributed into eight series for the brain and 4 series for the spinal cervical cord. Histological processing to visualise the tracers was described in detail previously (Rouiller et al., 1994a,b, 1996). The lesion site was reconstructed from camera lucida drawings of individual consecutive Nissl-stained sections of the spinal cervical cord. An alignment of the drawings allowed reconstruction of the location and extent of the lesion on a transverse view of the spinal cervical cord. A series of brain and spinal cord sections was treated immunocytochemically with SMI-32 antibody in order to visualise layers III and V pyramidal neurons, as recently described in detail (Liu et al., 2002). The epitope recognised by the SMI-32 antibody lies on non-phosphorylated regions of neurofilament protein and is only expressed by specific categories of neurons (Campbell and Morrison 1989; Tsang et al., 2000).

To evaluate the effect of the lesion on CS neurons, we selected coronal sections through motor cortical areas where no electrode penetration had been made. These areas were located in the medial wall of the gyri praecentralis in M1 and in the supplementary motor area (SMA; see inset in Fig. 2). On SMI-32 stained material, well stained lamina $V$ pyramidal cells were easily identifiable even using low magnification (x40). Since, some cells (particularly in the contralateral M1) were faintly stained and would have escaped observation at low magnification, the quantitative analysis was conducted using a higher magnification (x400) for a better discrimination. The number of SMI-32 stained lamina V cells and the projected surface of their cell body was obtained from digitised photomicrographs using appropriate software (Olympus DP $10 \AA$ and Neurolucida®). The neurons included in this analysis were SMI-32 positive, had a visible nucleus and were located in layer $V$ (Figs. 2 and $3 \mathrm{~A}$ ). Because of the presence of large apical dendrites, the limits of the soma along their axis was sometimes difficult to define, we therefore considered that, along large apical dendrites, the soma ended at a distance of $20 \mu \mathrm{m}$ from the nucleus (Fig. 3A). For comparison, brain sections from two intact animals (Ctrl1; Ctrl2), which had been included in a previous study (Liu et al., 2002), were used as control material for Nissl and SMI-32 analysis. 
Counts of SMI-32 positive neurons and measurements of their somatic cross-sectional area were performed for each of the four monkeys and on both hemispheres on 4 coronal sections taken in M1, separated by $800 \mu \mathrm{m}$ each, and on 4 coronal sections taken in SMA-proper, also separated by $800 \mu \mathrm{m}$ each. On each section, a segment of layer $\mathrm{V}$ of similar length was taken from each hemisphere along which the SMI-32 positive cells were counted. Overall, the total length of layer $\mathrm{V}$ analysed was the same in each hemisphere within each animal. Moreover, the thickness of the analysed sections was measured for each hemisphere in the zone of measurements, using Neurolucida to determine along the vertical axis the distance between points of focus adjusted to the top and to the bottom of the section. It was found that the sections shrank to a large degree (50 to $60 \%$ ) along the vertical axis but, importantly, the shrinkage was very similar for the two hemispheres of a given section. In other words, cell counts and somatic cross-sectional area measurements were performed on hemispheres of comparable thickness, for each section analyzed. Consequently, the quantitative comparisons regarding the number of pyramidal neurons and their somatic cross-sectional area have been conducted on comparable volumes of tissue in the two hemispheres.

To quantitatively compare the SMI-32 staining density in the laminae of the left and right M1, an image density analysis was performed. Microphotographs were first captured from four different SMI-32 stained sections using the same illumination and constant digital camera sensitivity. The microphotographs were stored as uncompressed black and white bitmap files, with the value of each pixel corresponding to the grey level (i.e. luminosity) of a specific section site. The microphotographs were oriented so that the cortex surface was on the left side, the cortex columns running on horizontal planes. The data were then read as a matrix using IDL $®$ software, in which the matrix lines contained the luminosity values along a cortical column and the matrix columns the luminosity values at a specific distance from the cortical surface. This procedure was repeated for four sections and the mean of all eight (left and right cortex) total density values calculated and plotted together with their standard deviation (Fig. 3D). 


\section{Results}

\section{1. $\underline{\text { Cervical cord lesion }}$}

The precise location of the CS axons in the cervical enlargement of normal monkeys was derived from material obtained in a previous study (Rouiller et al., 1996). As a result of unilateral injection of the anterograde tracer BDA in the hand representation in M1 of an intact monkey, labelled CS axons formed three tracts of fibres in the cervical cord (Fig. 1A). The majority of CS fibres occupied the contralateral dorso-lateral funiculus, representing $86 \%$ of all CS fibres labelled in this animal. Also in the dorsolateral funiculus, but ipsilateral to the injection in M1, CS axons were observed and represented a proportion of $12 \%$. Finally, a relatively small contingent of BDAlabelled fibres was found in the ipsilateral ventral funiculus (2\%). This distribution of CS axons at cervical level is largely consistent with that observed at lumbar level as a result of massive BDA injection in the M1 hindlimb area in macaque monkeys (Lacroix et al., 2004).

For both lesioned animals, the extent of the lesion was assessed by reconstructing the incision site from histological sections. In the first animal (Mk1; top panel in Fig. 1B), the knife cut most of the left dorsolateral funiculus, the lateral part of the ventral horn and the white matter lying immediately ventrally to the latter. The dorsal, the ventromedial and lateral part of the ventrolateral funiculi were preserved. This knife cut thus sectioned most if not all of the CS fibres descending through the left dorsolateral funiculus, but preserved the ventro-medial part and the undecussated CS fibres on the opposite side. In the second animal (Mk2; bottom panel of Fig. 1B), the section was larger and only the dorsal and the ventromedial funiculi were preserved on the lesioned side.

The BDA injections in the motor cortex contralateral to the lesion anterogradely stained the CS axons only to the upper cervical level, in spite of a survival time of 21 and 36 days in Mk1 and Mk2, respectively. In intact monkeys, a survival time of 20 days was sufficient for the BDA to be transported down to the thoraxic segments (Rouiller et al., 1996), suggesting that the axotomy of the CS tract substantially reduced the axonal transport rate of BDA. Consequently, BDA staining could not be used to visualise the interruption of the CS axons at the site of the knife cut. However, because axons of layer $\mathrm{V}$ neurons were strongly labelled for SMI-32 in the white matter underlying the cerebral cortex, we tried to stain a series of cervical cord sections for SMI-32. We observed the 
presence of SMI-32 positive axons in the spinal cord, corresponding to the CS axons as evidenced by their spatial distribution corresponding to the 3 groups of axons labelled with BDA after injection in the opposite M1 (Fig. 1A).

In both lesioned monkeys, on a transverse spinal cord section at thoracic level, the dorsolateral funiculus on the side contralateral to the lesion contained numerous SMI-32 stained axons Fig. 1C and E). In contrast, few or no SMI-32 stained axons were seen in the dorsal and dorsolateral funiculi on the ipsilateral side (Fig. 1C and D), except on its most dorsal aspect where ascending axons of the spino-cerebellar tract are passing. On transverse sections taken from the first cervical segments (above the hemisection), SMI-32 stained CS axons were observed bilaterally in the dorsolateral funiculus. On paralongitudinal sections at the level of the lesion, numerous stained fibres were seen in the dorsolateral funiculus rostral to the lesion, whereas very few remained visible in the dorsolateral funiculus caudal to the lesion (Fig. 1F). This observation suggests that the section interrupted most of the CS tract fibres running unilaterally in the dorsolateral funiculus. All SMI-32 stained CS axons ended about $1 \mathrm{~mm}$ above the level of the knife-cut (Fig. 1F) and the tip of some of them was swollen corresponding to retraction bulbs, indicative of a retraction process. To clarify if some spontaneous regeneration of the severed axons had occurred, we looked for the presence of processes crossing the site of the knife-cut as well as for axons bending away from their normal course to turn around the lesion. Neither SMI-32 labelled fibres crossing the knife-cut nor bent axons in the dorsolateral funiculus were observed. However, some few darkly stained processes were sometimes seen locally at the level of the lesion (Fig. 1F). As the intensity of their staining was different from that observed in CS axons in the dorsolateral funiculus, but was similar to that of dendrites in the adjacent grey matter, these structures were assumed to be dendrites of local neurons extending into the damaged tissue.

\section{Do CS neurons whose axon has been severed in the cervical cord degenerate?}

The hand area of $M 1$, in which repeated penetrations with tungsten electrodes were performed during the electrophysiological mapping and subjected to injection of BDA, was not suitable for an anatomical analysis of CS neurons. However, CS neurons in M1 represent about 
$35 \%$ of the whole CS population, the remaining CS neurons being dispersed mainly among nonprimary motor areas, such as the caudal portion of the supplementary motor cortex (SMA-proper), the premotor cortex (PM), the cingulate motor areas (CMA), and somatosensory areas. The analysis focussed on the mesial part of M1 and SMA proper (black rectangles in the inset of Fig. 2), whose vertical position above the cingulate sulcus allowed an easy comparison between the two hemispheres on the same coronal section. This M1 region contains CS neurons which normally project down to the lumbar segments but whose axons have been sectioned by the cervical hemisection. The analysis was extended rostrally to include SMA-proper. To avoid counting bias related to the presence of cortex curvatures, the quantitative analysis was restricted to regions where the cell columns are perpendicular to the cortical surface. On Nissl-stained sections, the ipsilateral M1 (Fig. 2A) and SMA-proper were characterised by the presence of numerous and large perikaria in layer $\mathrm{V}$ (typical pyramidal cells), the layer of origin of the CS tract. In the contralateral M1 (Fig. 2B) and SMA proper, in contrast, the layer $\mathrm{V}$ appeared strongly impoverished of large pyramidal cell bodies. The same observations were made on SMI-32 stained material (Fig. 2C and D).

These preliminary qualitative observations suggest that the large pyramidal cells of layer $\mathrm{V}$ in the contralateral hemisphere may have degenerated as a result of the cervical lesion. Alternatively, the neurons could also have shrunken and/or reduced their expression of non-phosphorylated neurofilaments, thereby losing their strong SMI-32 staining. In fact, faintly stained neurons were rather frequent in the contralateral M1 and SMA-proper (Fig. 3A) and can easily escape detection at low magnification (40x). The lamina $\mathrm{V}$ neurons were therefore analysed quantitatively at higher magnification (400x): they were counted and their somatic cross-sectional area was measured on sections taken at several rostro-caudal coordinates.

The analysis was conducted in the two lesioned monkeys and, for comparison, on material taken from two unlesioned animals (Ctrl1, Ctrl2). For each monkey, in both M1 and SMA-proper, the number of SMI-32 positive neurons in layer $V$ was comparable between the two hemispheres (Fig. 3B). To investigate whether CS cells' shrinkage took place as a result of the cervical lesion, measurements of somatic cross-sectional area were performed in each monkey and each 
hemisphere, separately for M1 and SMA-proper (Fig. 4). The median values of somatic crosssectional areas of SMI-32 positive neurons in layer $\mathrm{V}$ obtained in $\mathrm{M} 1$ in the two intact animals ranged from 329 to $631 \mu \mathrm{m}^{2}$. In the lesioned monkeys, the range of median values of somatic cross-sectional areas in the left hemiphere (ipsilateral to the cervical hemisection) was 401 to 627 $\mu \mathrm{m}^{2}$. In SMA-proper, the median values of somatic cross-sectional areas ranged from 253 to 594 $\mu \mathrm{m}^{2}$ across hemispheres and animals. In $\mathrm{M} 1$, the box plot distribution and the statistical analysis show that the somatic cross-sectional areas in the two intact monkeys (Ctrl1 and Ctrl 2) do not differ significantly between the left and the right hemispheres. In contrast, in the two lesioned animals (Mk1 and Mk2), the somatic cross-sectional areas of the SMI-32 positive neurons in layer $V$ were significantly smaller in the (right) hemisphere affected by the cervical hemisection than in the (left) ipsilesional hemisphere (Fig. 4, top panel). In SMA-proper, no statistically significant difference of somatic cross-sectional area was observed between the two hemispheres in both intact and lesioned monkeys (Fig. 4, bottom panel).

The same measurements of somatic cross-sectional area of SMI-32 immunoreactive layer V pyramidal neurons were further analyzed by focusing on the distribution of the $20 \%$ largest and $20 \%$ smallest cells. The somatic cross-sectional area values were ranked from the smallest to the largest. For each soma area value, we determined whether the corresponding SMI-32 positive layer $\mathrm{V}$ neuron was located in the left versus right hemisphere. Two sub-populations of layer $\mathrm{V}$ neurons, each amounting to $20 \%$ of the cells of the whole population, were then investigated separately. The first one pooled the neurons with the lowest soma areas (lower 20 percentile), and the second one pooled those with the largest soma areas (upper 20 percentile). The numbers of neurons from each hemisphere in each of these two sub-populations were calculated and plotted. For the lesioned animals and in M1, the results indicate that the majority of the largest cells were located in the ipsilateral hemisphere and that the majority of the smallest neurons were located in the contralateral hemisphere (Fig. 3C). These differences were statistically significant (Chi-square test, $\mathrm{p}<0.05$ ). For the unlesioned animals such differences were not observed in M1 (Chi-square test, $p>0.05$ ), and somatic cross-sectional areas were comparable in both hemispheres. These data therefore indicate that following a section of their axons in the cervical cord, the CS neurons in 
M1 underwent histological changes, such as a shrinkage of their volume and/or a reduction of expression of non-phosphorilated neurofilaments. In contrast, no massive neuronal cell death could be demonstrated, since there was no significant decrease of the cell number in the hemisphere contralateral to the lesion. A same distribution of SMI-32 positive neurons based on their somatic areas in the $20 \%$ lower and upper percentiles in SMA-proper (not shown) did not exhibit a statistically significant difference between the two hemispheres in both the intact and normal animals, on the contrary to M1 (Fig. 3C). This negative result in SMA-proper is consistent with the absence of significant difference in the somatic areas distribution (Fig. 4, bottom panel).

To clarify if the changes were restricted to lamina $V$ or if they also affected lamina III neurons, the staining density of four microphotographs of the left and right M1 have been calculated and compared. The results indicate that the mean density was comparable in both hemispheres for layers I to IV, but decreased for layer $V$ in the contralateral hemisphere as compared to the ipsilateral one (Fig. 3D).

\section{Discussion}

\section{Extent of the cervical lesion}

Following a hemisection of the cervical cord at level $\mathrm{C} 7 / \mathrm{C} 8$, most pyramidal neurons in layer $\mathrm{V}$ of the contralateral motor cortex survived. However, in $\mathrm{M} 1$, the axotomized neurons exhibited a significant shrinkage of their soma and a parallel decrease of SMI-32 immunoreactivity. In the spinal cord, SMI-32 immunocytochemistry allowed to visualized the CS axons and thus to evaluate the extent of the contingent of CS axons severed. To our knowledge, this is the first observation that SMI-32 stains not only the soma of pyramidal cells, but also their axons in the white matter, at least for the axons emitted by the CS neurons. This observation indicates that the CS neurons are thus included in the pool of SMI-32 positive pyramidal cells in layer V. A critical evaluation of the lesion position and extent indicated that most of the left dorsolateral funiculus was sectioned in both animals, although a small proportion may have been spared in Mk1. In spite of the absence of direct quantitative measures, it seems safe to estimate that $80-90 \%$ of the drive normally provided 
directly by the CS system to spinal segments caudal to the lesion (and including that of the spared uncrossed projections) was eliminated. This important loss of descending influence was corroborated by the flaccid paresis of the hand and leg observed immediately after the lesion and by the inefficacy of intracortical microstimulation (ICMS) to elicit hand and finger movements during the period immediately following the lesion (Schmidlin et al., 2004).

\section{Cross-sectional somatic area measurements}

The quantification of SMI-32 positive neurons in layer $\mathrm{V}$, together with the determination of their somatic cross-sectional area, led to our conclusion that most axotomized CS neurons in M1 survived but shrank (Figs. 3 and 4). Indeed, in each of the two animals subjected to a unilateral section of the main CS tract at cervical level, SMI-32 positive neurons in layer $\mathrm{V}$ of M1 contralateral to the lesion are significantly smaller than those located in M1 ipsilateral to the lesion, but their number does not change significantly. In the two control animals, no somatic area or number difference for SMI-32 positive neurons could be detected in M1 between the two hemispheres. The probability to obtain by chance this configuration of observations (two lesioned animals with an interhemispheric difference in somatic area and two control animals without difference) is low, amounting to about 0.11 . Because of the small number of animals $(n=4)$, this figure is not statistically significant in the usual sense $(p<0.05)$; however, these data can be considered as strongly suggestive.

The values of somatic cross-sectional areas of SMI-32 positive pyramidal neurons in layer $\mathrm{V}$ obtained in M1 (Fig. 4) showed a substantial variability within an individual animal, as well as across monkeys. However, the soma areas values are generally consistent with the average diameter of $34.5 \mu \mathrm{m}$ reported for CS neurons in Macaca mulata (Nudo et al., 1995), as well as with the range of diameters (10 to $58 \mu \mathrm{m}$ ) obtained from CS neurons retrogradely labelled as a result of tracer injection in the spinal cord (Murray and Coulter, 1981). More directly, the somatic crosssectional area values of Figure 4 are consistent with the areas derived from the dimensions of six intracellularly labelled CS neurons (Gosh and Porter, 1988), ranging from 650 to $1000 \mu \mathrm{m}^{2}$. A large variability of perikaryal size has also been reported in general for pyramidal cells in the cat, in 
sensory cortices and, even more pronounced, in the motor cortex (see Feldman, 1984). In addition to inter-individual differences, different shrinkage factors of the tissue during fixation and histological processing may explain the wide inter-animal variability (Fig. 4). The shrinkage of the CS axotomized neurons after the cervical hemisection appeared clearly in M1 but, in SMA-proper, the soma areas tended to be smaller (but not significantly) in the hemisphere contralateral to the lesion compared the ipsilateral one (Fig. 4). The less dramatic impact of the lesion on SMA-proper as compared to M1 in term of shrinkage of the axotomized neurons, as seen in Figure 4, can be explained by the lower number of CS neurons in SMA-proper than in M1. Therefore, measurements conducted on a general population of pyramidal neurons in layer $\mathrm{V}$ involve proportionally less axotomized CS neurons in SMA-proper than in M1, explaining why the difference was smaller in the former than the latter area.

\section{Technical considerations}

The reduction of the anterograde transport velocity of BDA after injection in the contralateral M1 in Mk1 and Mk2 was unexpected. In intact animals, the transport time that we used here would have been fully sufficient to stain CS fibres down to the thoracic segments (see Rouiller et al., 1996), whereas in the two lesioned animals, it only enabled to stain CS axons down to the rostral most cervical segments. In young and juvenile macaques subjected to a spinal hemisection similar transport times were used successfully for retrograde transport (Galea and Darian-Smith 1997a). The reasons for the slow transport velocity in the present study are unknown, but the age of the animals at the time of the lesion as well as the duration of the survival time following the lesion could contribute to this discrepancy. In rodents, axotomy reduces the retrograde transport velocity in a way that varies in function of the time from the moment of the lesion to that of the injection of the tracer (Tseng et al., 1995).

CS cells survival after transection of the CS tract: comparison with previous studies

Cell death has long been used as tracing method (retrograde degeneration) enabling identification of the cells of origin and the course of projecting systems, although its feasibility has 
been questioned (see e.g. Kuypers 1981). Following a section of the CS tract, such changes have been reported in the layer $\mathrm{V}$ of motor cortex of primates (Levin and Bradford 1938; Pernet and Hepp-Reymond 1975; Walker and Richter 1966), including human subjects (Holmes and May 1909; Wohlfarth 1932). In the macaque monkey, a quantitative analysis of Nissl stained material indicated that up to $63 \%$ of the pyramidal cells disappeared from layer $\mathrm{V}$ following a complete unilateral pyramidal transection (pyramidotomy) and that the large pyramidal neurons were more affected than the small ones (Pernet and Hepp-Reymond 1975). Our low magnification observations on Nissl and SMI-32 stained material (Fig. 2) would lead to conclusions consistent with these previous studies, suggesting that many large pyramidal neurons may have disappeared from layer V in M1 and SMA-proper. However, our quantitative analysis of the SMI-32 stained material at high magnification led to another conclusion. SMI-32 positive cells are mostly projecting neurons and, in the intact animal, the large layer $\mathrm{V}$ neurons in $\mathrm{M} 1$, presumably $\mathrm{CS}$ neurons, belong to the well stained elements (Campbell and Morrison 1989). In our experiments, the comparison of both hemispheres for the number of SMI-32 stained neurons in M1 and in SMAproper did not show any significant cell loss in the hemisphere contralateral to the lesion. However, comparison of the somatic cross-sectional area of the stained cells in both hemispheres showed that the layer $\mathrm{V}$ neurons in $\mathrm{M} 1$ are significantly smaller in the contralateral hemisphere, thus indicating shrinkage of these neurons. In addition, the intensity of the SMI-32 cell staining was fainter in the hemisphere opposite to the lesion. These observations indicate that the layer $\mathrm{V}$ neurons survived but shrank. The shrinkage of the large pyramidal cells and the decrease of SMI32 immunoreactivity could account for the discrepancy of the observations made at different magnifications in Nissl and SMI-32 stained material. The large cells shrank to the dimensions of other layer $\mathrm{V}$ neurons and thus lost their typical appearance in Nissl stained sections. The survival of at least a large portion of the CS neurons is confirmed by several other observations, which also demonstrated that the damaged CS fibres still reach the spinal segments rostral to the lesion. Firstly, retrogradely stained neurons in the hand and foot region of the contralateral M1 were found after injecting a retrograde tracer just rostrally to a cervical spinal hemisection (Galea and DarianSmith 1997a). Secondly, although the transport time was inadequate to stain CS axons down to 
the lesion site, BDA injections in the M1 hand region of Mk1 and Mk2 stained numerous fibres down to the pyramids and entered the first cervical segments. Thirdly, our SMI-32 stained material showed positive axons in the dorsolateral funiculi at locations rostral to the lesion, presenting a comparable pattern of labelling of CS axons on both sides. Caudal to the lesion, SMI-32 stained axons almost entirely disappeared from the dorsolateral funiculus on the lesioned side. Since the axons of numerous large layer $\mathrm{V}$ pyramidal cells of M1 are SMI-32 positive, many of the stained axons in the dorsolateral funiculus are presumably CS axons. Altogether these data show that the sectioned CS axons survived and did not retract significantly from the lesion level (not more than $0.5-1 \mathrm{~mm}$; Fig. 1F). This is in accordance with the distribution of apoptotic elements in the spinal cord of lesioned monkeys which are mainly found in the white matter caudal to a lesion affecting descending tracts (Crowe et al., 1997). These considerations and the present SMI-32 data contradict the notion of a substantial loss of CS neurons after lesion of the spinal cord in primates, as suggested by some authors on the basis of Nissl-stained material (Holmes and May, 1909; Levin and Bradford, 1938; Pernet and Hepp-Reymond, 1975; Wohlfarth, 1932). How to reconcile then the present observation of a survival of axotomized CS neurons with these retrograde degeneration data reported earlier? First of all, shrunken but rescued CS neurons may have been interpreted as a disappearance of large layer $\mathrm{V}$ neurons, as this can be seen on Nissl material, especially at low magnification (Fig. 2). The use of the specific SMI-32 marker represents a clear advantage over Nissl material, to better identify the relevant population of neurons on which to perform counts and measurements. Secondly, most retrograde degeneration studies are cases in which the CS tract lesion was a pyramidotomy, a lesion thus located closer from the soma than our cervical hemisection, leading to a higher probability of cell loss than after a more caudally located lesion. The latter explanation is however unlikely because in one of these earlier studies the lesion was at cervical level and the authors concluded a significant cell loss had occurred (Holmes and May, 1909), in contrast to the present results.

However, several observations in the literature in the primate and in Nissl material are consistent with the present results. Indeed, Tower (1940), Lassek (1948), Bronson et al. (1978) all reported a large survival of CS axotomized neurons, irrespective of whether the lesion was a 
pyramidotomy or affected the spinal cord itself. In particular, Lassek (1948) reached this conclusion based on a highly careful examination of cell size and cell appearance in layer $\mathrm{V}$, as we did here using another marker, SMI-32. These detailed observations in both NissI and SMI-32 materials demonstrate that the axotomized CS neurons lost some of their typical appearance and shrank, changes that were apparently not detected by the authors concluding to cell loss, possibly because they focussed their observations on the large layer $V$ neurons without paying enough attention to smaller (shrunken) pyramidal cells.

The same controversy appears to be present in rodents. In the rat, it has recently been demonstrated that, after transection of the main CS tract (95\% of CS axons, running in the dorsal funiculus) at T9 level, a significant proportion (40\%) of the CS neurons projecting to this thoracic level underwent apoptosis one week after injury (Hains et al., 2003). At four weeks after injury, cell loss of CS neurons was around $35-40 \%$. As discussed by the authors, considering that about $40 \%$ of CS axons reach the T9 level, the cell loss thus represents about $14 \%$ of all CS neurons. In the present study, considering that the lesion was at cervical level, a comparable rate of cell loss would have resulted in a substantially larger loss of cell. The data presented in Figure 3 argue that, in contrast to the rat, there was no cell loss after cervical cord hemisection in the monkey. To explain such a species difference, one should consider that, in the monkey, the CS axons have been axotomized at a distance from the soma longer than in the rat, assuming that the further the lesion is from the soma the higher is the probability of survival. One may also speculate that CS axons in the monkey may give rise to more collateral projections, establishing contacts which may favour survival. More relevant maybe to explain the discrepancy between the rat and the monkey lies in the extent of the CS transection, which was bilateral in the rat (Hains et al., 2003) whereas it was unilateral in the present monkey experiments.

The evidence of cell loss in the rat (Hains et al., 2003) is, however, challenged by a study conducted in hamsters (Kalil and Schneider, 1975), showing clear evidence for a survival of most CS axotomized neurons after unilateral pyramidotomy. This latter observation argues against the notion that a section of the axon relatively close to the soma leads to a retrograde degeneration up to the cell body. Indeed, Kalil and Schneider (1975) observed that the retrograde degeneration of 
the axon was limited to a distance of $6-7 \mathrm{~mm}$. The main difference between the two studies is that the observation of Hains et al. (2003) were made after a survival time of 4 weeks, whereas Kalil and Schneider (1975) followed the changes up to 14 months.

What then is the difference between the studies arguing for a cell loss and those arguing for a cell survival, making the latter more plausible? Cell loss was a conclusion drawn from observations limited to the soma of the CS neurons in the cerebral cortex and without quantification of somatic cross-sectional areas. In contrast, the studies supporting the scenario of cell survival not only examined quantitatively and in detail the situation in the cerebral cortex (counts of cells and measurements of soma areas), but also looked in detail at the status of the CS axons rostral to the lesion. These reports (Kalil and Schneider, 1975; Tower, 1940) and the present study all provide evidence that the CS transected axons underwent a retrograde degeneration, but limited to a short distance above the lesion (a few $\mathrm{mm}$ ), consistent with a survival of the soma of origin.

\section{Considerations related to the recovery from CS tract lesion}

As described in a separate report (Schmidlin et al., 2004), the two monkeys subjected to the cervical cord lesion exhibited a spontaneous, incomplete recovery of the hand manual dexterity reaching, after about 50 days, a level of 70 and $20 \%$ of the pre-lesion behavioural score in Mk1 and Mk2, respectively. One may think that the absence of death among the axotomized CS neurons is a factor favourable for such a remarkable spontaneous recovery. The large survival of axotomized CS neurons in primates thus represents a good news in the context of developing treatments aimed at enhancing such recovery. Indeed, in primates, a rapid treatment post-lesion aimed at preventing cell loss does not seem necessary. In other words, in primates, treatments can be directly focussed on promoting regeneration of transected CS axons and/or triggering the recruitment of minor CS tracts preserved by the lesion. It has been shown that such preserved minor CS tracts can give rise to axonal sprouting, as observed in the rat even in absence of treatment (Weidner et al., 2001). The large survival of axotomized CS neurons in primates is thus favourable for promoting compensatory sprouting from the transected axons along their trajectory, 
in order to recruit other descending pathways (e.g. rubrospinal projection), allowing a re-routing of motor commands to the motoneurons. Such a mechanism of compensatory sprouting was demonstrated to be enhanced in rats subjected to unilateral or bilateral pyramidotomy or to motor cortex lesion and treated with an antibody neutralising the neurite growth inhibition protein "Nogo" (Raineteau et al., 1999, 2001, 2002; Wenk et al., 1999; Z'Graggen et al., 1998). The two monkeys subjected to cervical hemisection in the present study are animals representing a model to assess the degree of recovery after such a lesion, that will be compared in the near future to monkeys subjected to the same lesion but treated with the antibody neutralising "Nogo".

\section{Acknowledgements}

The authors wish to thank the technical assistance of Véronique Moret, Françoise Tinguely and Christine Roulin (histology and behavioural evaluations), Josef Corpataux and Bernard Morandi (animal house keeping), André Gaillard (mechanics), Bernard Aebischer (electronics), Laurent Monney (informatics). We thank Dr. Clive Brown for valuable comments on the manuscript. 


\section{References}

AOKI, M., and MORI, S. (1979). Recovery of hindlimb movement elicited by motor cortical stimulation after spinal hemisection in monkeys. In Ito M (Ed.) Integrative control functions of the brain. Elsevier: Amsterdam, pps. 152-154.

BECK, C.H., and CHAMBERS, W.W. (1970). Speed, accuracy, and strength of forelimb movement after unilateral pyramidotomy in Rhesus monkeys. J. Comp.and Physiol. Psychol. (Monograph) 2, part 2, 1-22.

BERNHARD, C.G., BOHM, E., and PETERSEN I. (1953). Investigations on the organization of the corticospinal system in monkeys. Acta Physiol. Scand. 29, 79103.

BRONSON, R., GILLES, F.H., HALL, J., and HEDLEY-WHYTE, E.T. (1978). Long term post-traumatic retrograde corticospinal degeneration in man. Hum.Pathol. 9, 602607.

BUCY, P.C. (1957). Is there a pyramidal tract? Brain 80, 376-392.

BUCY, P.C. (1966). Destruction of the pyramidal tract in the monkey. J.Neurosurg. 25, 120.

CAMPBELL, M.J., and MORRISON, J.H. (1989). Monoclonal antibody to neurofilament protein (SMI-32) labels a subpopulation of pyramidal neurons in the human and monkey neocortex. J. Comp. Neurol. 282, 191-205.

CHAPMAN, C.E., and WIESENDANGER, M. (1982). Recovery of function following unilateral lesions of bulbar pyramid in the monkey. Electroenceph. Clin. Neurophysiol. 53, 374-387.

CROWE, M.J., BRESNAHAN, J.C., SHUMAN, S.L., MASTERS, J.N., and BEATTIE, M.S. (1997). Apoptosis and delayed degeneration after spinal cord injury in rats and monkeys. Nat. Med. 3, 3-76. 
DAVISON, C. (1937). Syndrome of the anterior spinal artery of the medulla. Arch. Neurol. Psychiat. 37, 91-107.

DENNY-BROWN, D. (1966). The Cerebral Control of Movements. Liverpool, Liverpool University Press: Liverpool, pps 37-53.

FELDMAN, M.L. (1984) Morphology of the neocortical pyramidal neuron. In: Cerebral Cortex, Vol. 1: Cellular components of the Cerebral Cortex, Eds. Peters, A. and Jones, E.G., Plenum Press, New-York and London, pp. 123-200.

GALEA, M.P., and DARIAN-SMITH, I. (1997a). Corticospinal projection patterns following unilateral section of the cervical spinal cord in the newborn and juvenile macaque monkey. J. Comp. Neurol. 381, 282-306.

GALEA, M.P., and DARIAN-SMITH, I. (1997b). Manual dexterity and corticospinal connectivity following unilateral section of the cervical spinal cord in the macaque monkey. J. Comp. Neurol. 381, 307-319.

GOSH, S., and PORTER, R. (1988). Morphology of pyramidal neurons in monkey motor cortex and the synaptic actions of heir intracortical axon collaterals. J. Physiol. 400, 593-615.

HAINS, B.C., BLACK, J.A., and WAXMAN, S.G. (2003). Primary cortical motor neurons undergo apoptosis after axotomizing spinal cord injury. J. Comp. Neurol. 462, 328341.

HEPP-REYMOND, M.C., and WIESENDANGER, M. (1972). Pyramidotomy in monkeys: effect on force and speed of a conditioned precision grip. Brain Res. 36, 117-131. HEPP-REYMOND, M.C., TROUCHE, E., and WIESENDANGER, M. (1974) Effects of unilateral and bilateral pyramidotomy on a conditioned rapid precision grip in monkeys (Macaca fascicularis). Exp. Brain Res. 21, 519-527.

HEPP-REYMOND, M.C. (1982). Lésions expérimentales dans le système nerveux central. Pädiat. Fortbildk. Praxis 53, 160-177. 
HOLMES, G., and MAY, W.P. (1909). On the exact origin of the pyramidal tracts in man and other mammals. Brain 32, 1-43.

JENNY, A.B., and INUKAI, J. (1983). Principles of motor organization of the monkey cervical spinal cord. J. Neurosci. 3, 567-575.

KALIL, K., and SCHNEIDER, G.E. (1975). Retrograde cortical and axonal changes following lesions of the pyramidal tract. Brain Res. 89, 15-27.

KUCERA, P., and WIESENDANGER, M. (1985). Do ipsilateral corticospinal fibers participate in the functional recovery following unilateral pyramidal lesions in monkeys? Brain Res. 348, 297-303.

KUYPERS, H.G.J.M. (1981). Anatomy of descending pathways. In Brooks VB (Ed.) Handbook of Physiology (The Nervous System), vol. II, part 1. Bethesda, MD, Am. Physiol. Soc. pps. 597-666.

LACROIX, S., HAVTON, L.A., McKAY, H., YANG, H., BRANT, A., ROBERTS, J., and TUSZYNSKI, M.H. (2004) Bilateral corticospinal projections arise from each motor cortex in the macaque monkey: a quantitative study. J. Comp. Neurol. 473, 147-161.

LASSEK, A.M. (1942). The pyramidal tract. A study of retrograde degeneration in the monkey. Arch. Neurol. Psychiat. 48, 561-567.

LAWRENCE, D.G., and KUYPERS, H.G.J.M. (1968). The functional organization of the motor system. I. The effects of bilateral pyramidal lesions. Brain 91, 1-14.

LAWRENCE, D.G., and HOPKINS, D.A. (1976). The development of motor control in the Rhesus monkey: evidence concerning the role of corticomotoneuronal connections. Brain 99, 235-254.

LEVIN, P.M., and BRADFORD, F.K. (1938). The exact origin of the cortico-spinal tract in the monkey. J. Comp. Neurol. 68, 411-422. 
LIU, J., MOREL, A., WANNIER, T., and ROUILLER, E.M. (2002). Origins of callosal projections to the supplementary motor area (SMA): a direct comparison between pre-SMA and SMA-proper in macaque monkeys. J. Comp. Neurol. 443, 71-85.

LIU, Y., and ROUILLER, E.M. (1999). Mechanisms of recovery of dexterity following unilateral lesion of the sensorimotor cortex in adult monkeys. Exp. Brain Res. 128, 149-159.

METTLER, F.A. (1944). Observations on the consequences of large subtotal lesions of the simian spinal cord. J. Comp. Neurol. 81, 339-360.

MURRAY, E.A., and COULTER, J.D. (1981). Organization of corticospinal neurons in the monkey. J. Comp. Neurol. 195, 339-365.

NUDO, R.J., SUTHERLAND, D.P., and MASTERTON, R.B. (1995). Variation and Evolution of mammalian corticospinal somata with special reference to primates. J. Comp. Neurol. 358, 181-205.

PAXINOS, G., HUANG, X.F., and TOGA, A.W. (2000). The rhesus monkey brain in stereotaxic coordinates. London; San Diego: Academic Press, pp. 1-165.

PERNET, U., and HEPP-REYMOND, M.C (1975). Retrograde Degeneration der Pyramidenbahnzellen im motorischen Kortex beim Affen (Macaca fascicularis). Acta Anat. (Basel) 91, 552-561.

RAINETEAU, O., FOUAD, K., NOTH, P., THALlMAIR, M., and SCHWAB, M.E. (2001). Functional switch between motor tracts in the presence of the mAb IN-1 in the adult rat. Proc. Natl. Acad. Sci. USA 98, 6929-6934.

RAINETEAU, O., FOUAD, K., BAREYRE, F.M., and SCHWAB, M.E. (2002). Reorganization of descending motor tracts in the rat spinal cord. Eur. J. Neurosci. 16, $1761-1771$.

RAINETEAU, O., Z'GRAGGEN, W.J., THALlMAIR, M., and SCHWAB, M.E. (1999). Sprouting and regeneration after pyramidotomy and blockade of the myelin- 
associated neurite growth inhibitors NI 35/250 in adult rats. Eur. J. Neurosci. 11, 1486-1490.

ROUILLER, E.M., BABALIAN, A., KAZENNIKOV, O., MORET, V., YU, X.H, and WIESENDANGER, M. (1994a). Transcallosal connections of the distal forelimb representations of the primary and supplementary motor cortical areas in macaque monkeys. Exp. Brain Res. 102, 227-243.

ROUILLER, E.M., LIANG, F., BABALIAN, A., MORET, V., and WIESENDANGER, M. (1994b). Cerebellothalamocortical and pallidothalamocortical projections to the primary and supplementary motor cortical areas: A multiple tracing study in macaque monkeys. J. Comp. Neurol. 345, 185-213.

ROUILLER, E.M., MORET, V., TANNÉ, J., and BOUSSAOUD, D. (1996). Evidence for direct connections between the hand region of the supplementary motor area and cervical motoneurons in the macaque monkey. Eur. J. Neurosci. 8, 1055-1059.

SASAKI, S., ISA, T., PETTERSSON, L.G., ALSTERMARK, B., NAITO, K., YOSHIMURA, K., SEKI, K. and OHKI, Y. (2004). Dexterous finger movements in primate without monosynaptic corticomotoneuronal excitation. J. Neurophysiol. (published on-line June $2^{\text {nd }}, 2004:$ 10.1152/jn.00342.2004).

SCHMIDLIN, E., WANNIER, T., BLOCH, J., and ROUILLER, E.M. (2004). Progressive plastic changes in the hand representation of the primary motor cortex parallels incomplete recovery from a unilateral section of the corticospinal tract at cervical level in monkeys. Brain Res. 1017, 172-183.

SCHWARTZMANN, R.J. (1978) A behavioral analysis of complete unilateral section of the pyramidal tract as the medullary level in Macaca mulatta. Ann.Neurol. 4: 234-244.

TOWER, S.S. (1940). Pyramidal lesion in the monkey. Brain 63, 36-90. 
TSANG, Y.M., CHIONG, F., KUZNETSOV, D., KASARSKIS, E., and GEULA, C. (2000). Motor neurons are rich in non-phosphorylated neurofilaments: cross- species comparison and alterations in ALS. Brain Res. 861, 45-58.

TSENG, G.F., SHU, J., HUANG, S.J., and WANG, Y.J. (1995). A Time Dependent Loss of Retrograde Transport Ability in Distally Axotomized Rubrospinal Neurons. Anat. Embryol. 191, 243-249.

WALKER, A.E. and RICHTER, H. (1966). Section of the cerebral peduncle in the monkey. Arch. Neurol. 14, 231-240.

WEIDNER, N., NER, A., SALIMI, N., and TUSZYNSKI, M.H. (2001). Spontaneous corticospinal axonal plasticity and functional recovery after adult central nervous system injury. Proc. Natl. Acad. Sci. U S A 98, 3513-3518.

WENK, C.A., THALLMAIR, M., KARTJE, G.L., and SCHWAB, M.E. (1999). Increased corticofugal plasticity after unilateral cortical lesions combined with neutralization of the IN-1 antigen in adult rats. J. Comp. Neurol. 410, 143-157.

WOHLFARTH, S. (1932). Die vordere Zentralwindung bei Pyramidenbahnläsionen verschiedener Art. Eine histopathologische Untersuchung. Acta Medica Scandinavica Suppl. 46, 1-235.

WOOLSEY, C.N., GORSKA, T., WETZEL, A., ERICKSON, T.C., EARLS, F.J., and ALLMAN, J.M. (1972). Complete unilateral section of the pyramidal tract at the medullary level in Macaca Mulatta. Brain Res. 40, 119-123.

Z'GRAGGEN, W.J., FOUAD, K., RAINETEAU, O., METZ, G.A.S., SCHWAB, M.E., and KARTJE, G.L. (2000). Compensatory sprouting and impulse rerouting after unilateral pyramidal tract lesion in neonatal rats. J. Neurosci. 20, 6561-6569. 
Figure 1

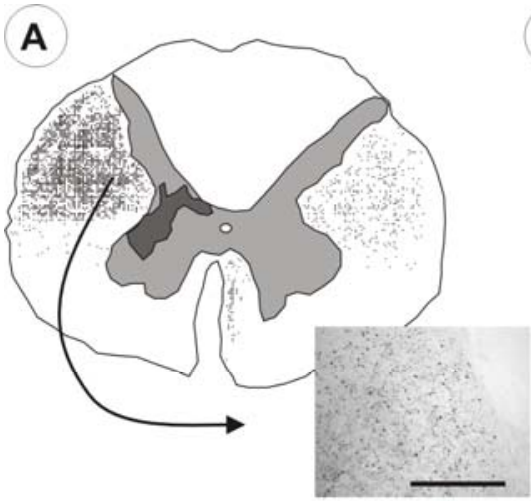

B

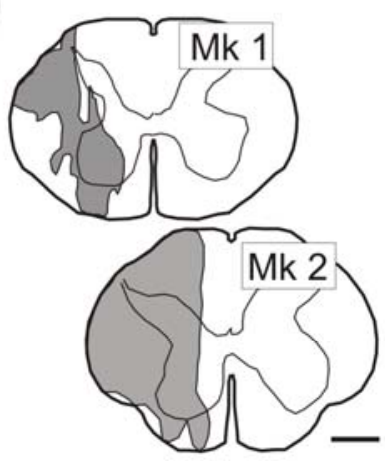

C

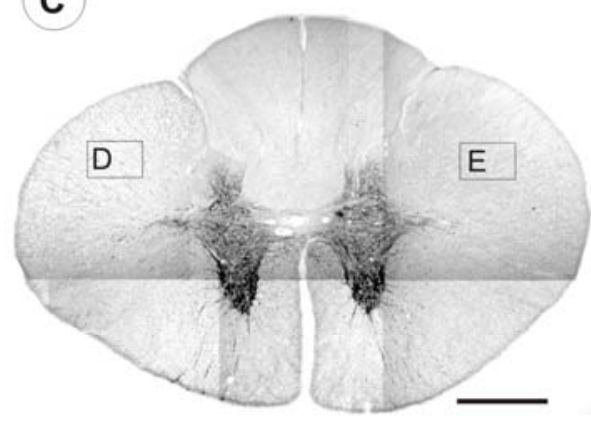

D

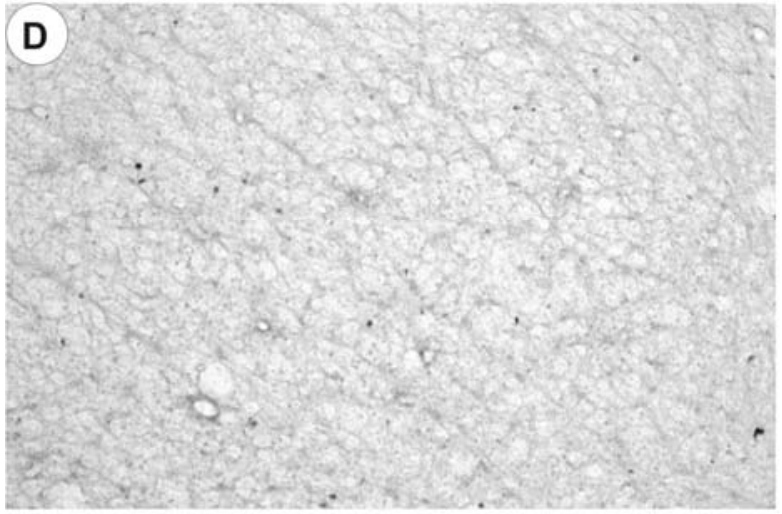

E
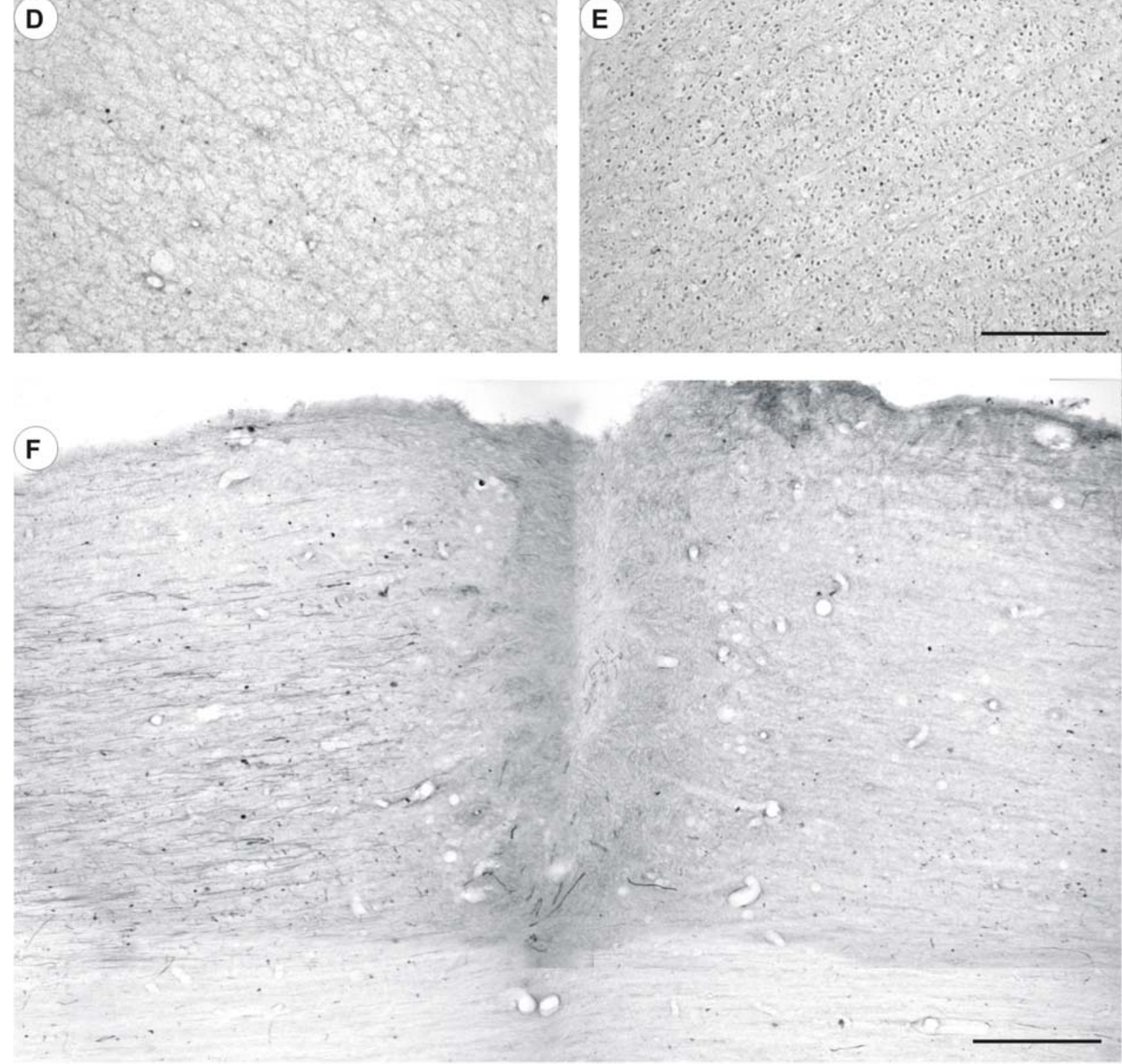

Fig. 1 


\section{Figure 2}
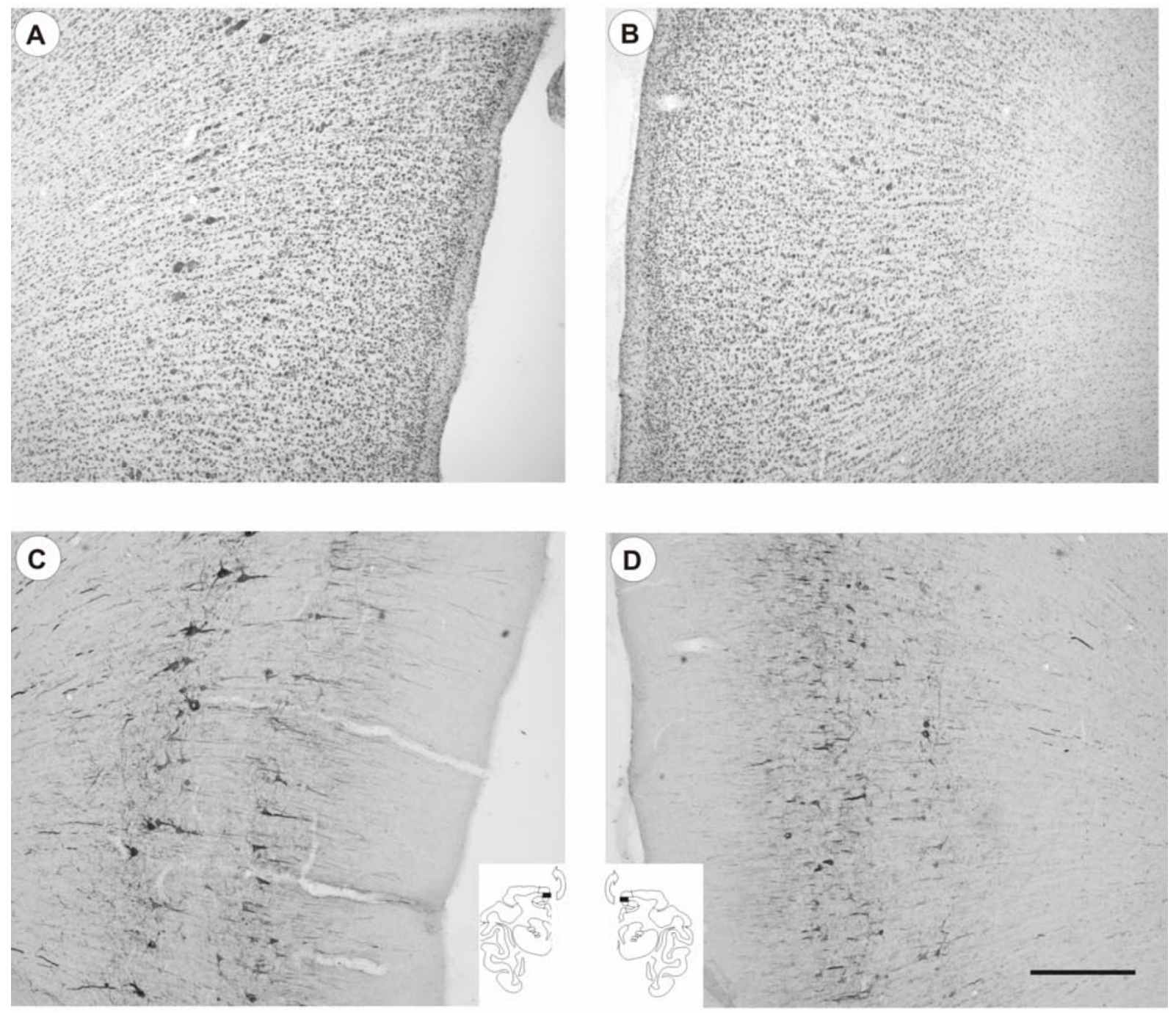

Fig. 2 
Figure 3
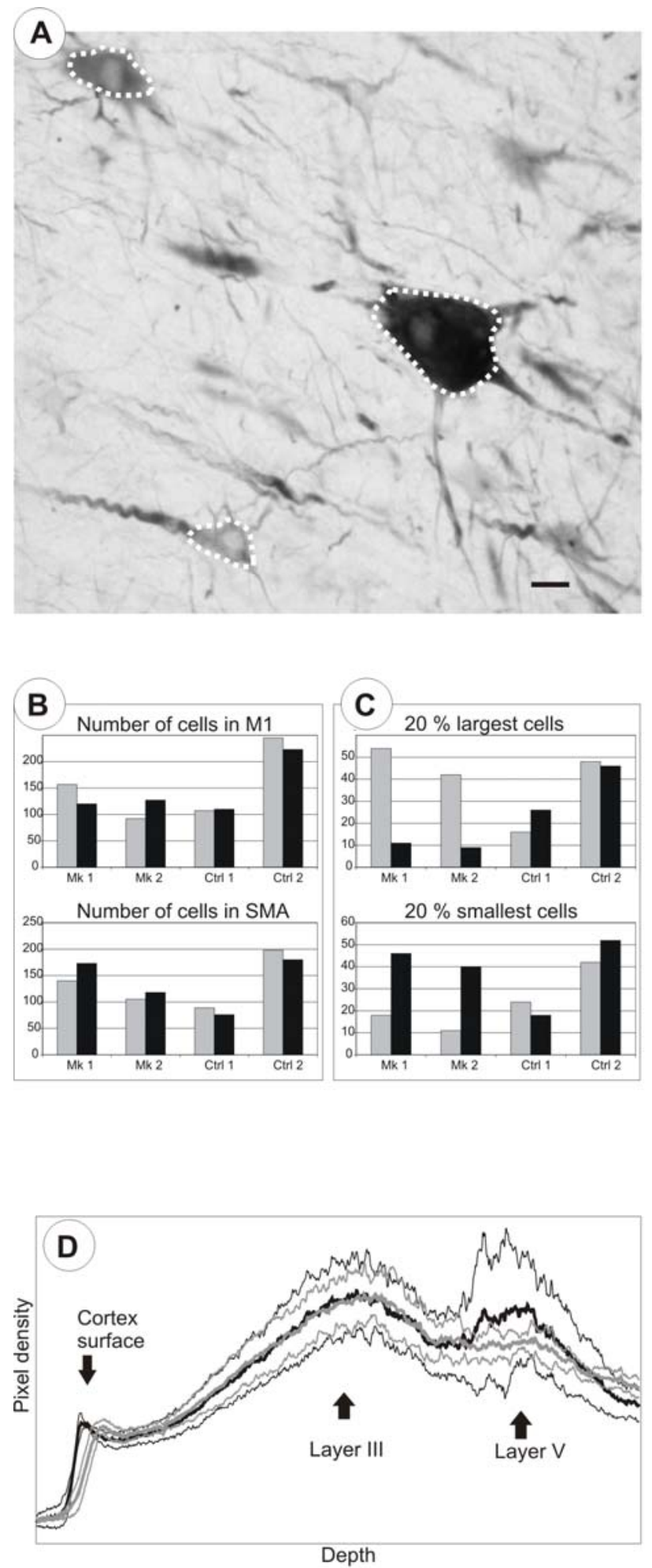

Fig. 3 
Figure 4
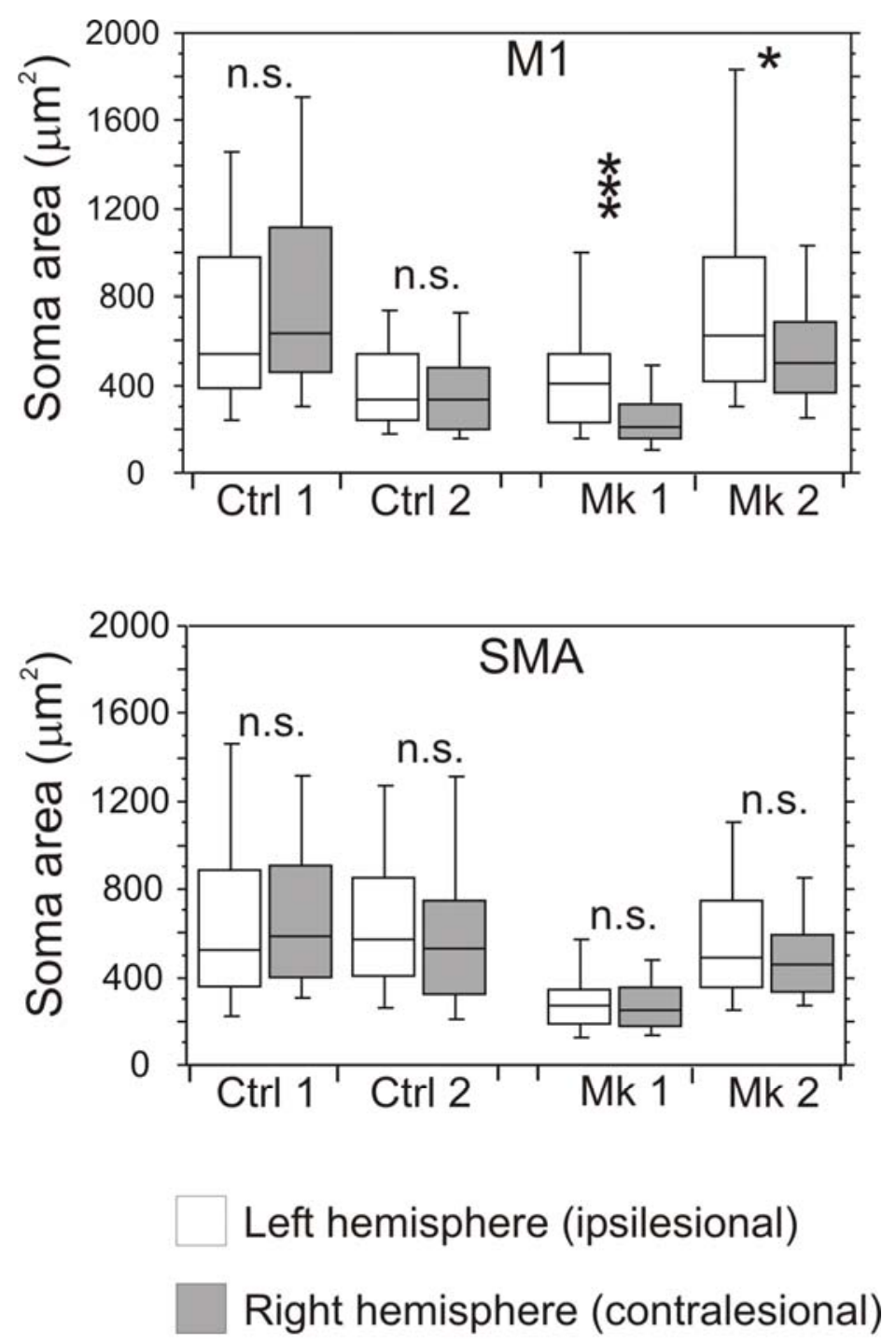

Fig. 4 


\section{Legend to Figures}

\section{Figure 1}

A: Transverse section of the cervical spinal cord at the upper part of the cervical enlargement showing the distribution of BDA labelled CS axons as a result of BDA injection in the right M1 of an intact monkey. These data were derived from a previous set of experiments (Rouiller et al., 1996). In the white matter, each labelled CS axon is represented by a dot corresponding to the position of its cut diameter when focussing on top of the section. The light grey area corresponds to the grey matter. The dark grey spot indicates the position of ramifying CS axons in the grey matter, thus forming a dense terminal field where boutons are visible. As indicated by the arrow, a small region of the section is illustrated by a photomicrograph, on which a part of the dorsolateral funiculus and a portion of the grey matter in the dorsal horn are visible (upper right part of the photomicrogaph). In the white matter, the cut CS axons labelled with BDA appear as black dots. See text for detailed and quantitative descriptions. Scale bar: $500 \mu \mathrm{m}$.

B: Location and extent of the lesion (grey area), performed at C7/C8 in Mk1 (top section) and Mk2 (bottom section). Scale bar $=2 \mathrm{~mm}$.

C.: Transverse section of the spinal cord caudal to the lesion and processed for SMI-32, on which rectangles display the position of the photomicrographs shown in panels $D$ and $E$. Scale bar: 1 $\mathrm{mm}$.

$\underline{D}$ and $\underline{E}$ : Density of SMI-32 stained CS axons in the left and right dorsal funiculi caudal to the left hemi-section. Labelled CS axons appear as a black dot. Note the paucity of CS axons below the lesion on the left side (D) in contrast to the right unlesioned side (E). Scale bar: $200 \mu \mathrm{m}$.

F: Paralongitudinal section of the spinal cord taken at the level of the lesion (vertical arrow) in Mk2. Note on the left (rostral to the lesion) the presence of numerous SMI-32 stained CS axons, whereas on the right (caudal to the lesion) no CS axon is visible. Scale bar: $500 \mu \mathrm{m}$.

\section{Figure 2}

$\underline{A}, \underline{B}, \underline{C}$ and $\underline{D}$ : Photomicrographs showing a part of $\mathrm{M} 1$ (hindlimb area) on both hemispheres in Mk1 on Nissl-stained (A and B) or on SMI-32 stained (C and D) histological sections. Note that the 
number of large Nissl-stained as well as large and darkly positive SMI-32 neurons in layer $\mathrm{V}$ was clearly higher in the left hemisphere $(A$ and $C)$ as compared to the right hemisphere ( $B$ and $D)$, as a result of a left hemi-section of the cervical cord at $C 7 / C 8$. Section $C / D$ is adjacent to section $A / B$. Scale bar: $500 \mu \mathrm{m}$. The inset in the bottom shows on each hemisphere with a black rectangle the zone in M1 and SMA-proper where counts of cells and somatic cross-sectional area measurements were made.

\section{Figure 3}

A: Photomicrograph of SMI-32 stained pyramidal cells in layer V of M1 on the right hemisphere, illustrating the typical staining restricted to pyramidal cells with their axons and dendrites. The three neurons are representative of the cell body sizes frequently met during the analysis. The nucleus is easily identifiable. The dashed outline illustrates the criteria applied in order to define the soma area (see methods). Scale bar: $20 \mu \mathrm{m}$.

B: Total number of SMI-32 stained cells in layer V of M1 and SMA-proper in the two lesioned monkeys (Mk1, Mk2) and, for comparison, in two intact monkeys (Ctrl1, Ctrl2), in the left (grey) and right (black) hemispheres. For the two lesioned monkeys, the right hemisphere is contralateral to the cervical lesion. Due to the relative large difference of the size of the analysed cortical region from one animal to another the total number varied from one animal to the next. However, there was no substantial difference between the two hemispheres within each animal.

C.: Same data as in B, but only for M1 and the numbers of SMI-32 stained neurons belonging to the $20 \%$ lowest or upper percentiles are indicated for each hemisphere. Clearly, the two lesioned monkeys showed a predominance of smallest neurons in the right hemisphere (black) whereas the largest neurons were found more frequently on the left hemisphere (grey).

D: Pixel density analysis along an axis perpendicular to the cortical surface on coronal sections of M1 stained with an antibody directed against neurofilaments of pyramidal cells (SMI-32). Data for the left hemisphere (homolateral to the lesion) are represented by the black lines, whereas the grey lines are for the right hemisphere (contralateral to the lesion). The average density values (thick lines, with standard deviations represented by the thin lines) exhibit a comparable peak of 
high density of SMI-32 staining in layer III of both hemispheres. In contrast, the peak of high density of SMI-32 staining in layer $\mathrm{V}$ is present only in the left hemisphere but not in the right hemisphere. This result supports the notion that the decrease of SMI-32 staining is limited to layer $\mathrm{V}$ of the contralesional side.

\section{Figure 4}

Box plots showing the distribution of somatic cross-sectional areas of SMI-32 positive neurons in layer V in M1 (top panel) and SMA-proper (bottom panel) for two intact animals (Ctrl1 and Ctrl2) and for the two lesioned monkeys (Mk1 and Mk2). The soma areas did not follow a normal distribution and therefore were graphically represented in the form of box plots (putting emphasis on the median value rather than the mean value). Accordingly, the statistical analysis was conducted using a non-parametric unpaired test (see below). In the box plots, the horizontal line in the box corresponds to the median value, whereas the top and bottom of the box are for the 75 and 25 percentile values respectively. The top and bottom extremities of the vertical lines on each side of the box are for the 90 and 10 percentile values, respectively. The white boxes are for the left hemisphere, ipsilateral to the cervical hemisection in the 2 lesioned monkeys. The gray boxes are for the right hemisphere, opposite to the lesion in the 2 lesioned monkeys. A statistical comparison between the two hemisphere was conducted for each animal using the non-parametric Mann and Whitney test. In M1, the two lesioned monkeys exhibited a significant difference of soma area across hemispheres $\left({ }^{*}=p<0.01 ;{ }^{* * *}=p<0.0001\right)$, whereas the other comparisons did not show any statistically significant difference (n.s. $=p>0.05)$. 